\title{
On the Nature and Accessibility of the Brønsted-Base Sites in Activated Hydrotalcite Catalysts
}

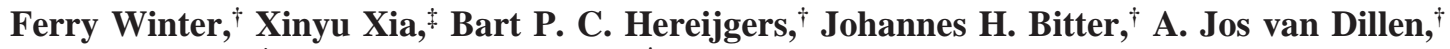 \\ Martin Muhler, ${ }^{*}$ and Krijn P. de Jong*, ${ }^{*}$ \\ Inorganic Chemistry and Catalysis, Department of Chemistry, Utrecht University, P.O. Box 80083 , \\ 3508 TB Utrecht, The Netherlands, and Laboratory of Industrial Chemistry, Ruhr-University Bochum, \\ D-44780 Bochum, Germany
}

Received: December 6, 2005; In Final Form: March 10, 2006

\begin{abstract}
Base catalysis is of importance for organic synthesis in general and fine chemicals manufacture in particular. Activated hydrotalcites have recently received a great deal of attention as solid base catalysts; however, no systematic work on the nature of their active sites has been published up till now. In this work two different methods have been applied to activate $\mathrm{Mg}-\mathrm{Al}$ hydrotalcites to obtain Brønsted-base catalysts for liquidphase condensation reactions. Activation via thermal treatment followed by rehydration (HT-reh) resulted in irregularly stacked platelets $(\sim 60 \mathrm{~nm})$, whereas the sample activated via aqueous ion-exchange (HT-exc) preserved its original hexagonal hydrotalcite platelets $(\sim 100 \mathrm{~nm})$. The specific activity for the self-condensation of acetone of HT-reh was over 10 times that of HT-exc. The enthalpy of $\mathrm{CO}_{2}$ adsorption on the activated hydrotalcites determined with calorimetry to gain insight into the strength of the basic sites showed very similar values. IR spectra of adsorbed $\mathrm{CDCl}_{3}$ as probe molecule on the differently activated samples revealed large differences in adsorbed amounts, but again the strength of the basic sites appeared to be the same. These results point to steric hindrance for the substrate molecules as the main factor determining differences in catalytic activity. The high accessibility of Brønsted-base sites in HT-reh is proposed to involve a distorted edge structure of the platelets. The edge structure of exchanged samples could be distorted too, either by exchange under reflux conditions or under ultrasonic treatment. In line with the proposed model, the distorted exchanged samples displayed a much higher catalytic activity than HT-exc.
\end{abstract}

\section{Introduction}

In recent years hydrotalcites (HT) have received increasing attention in the search for environmentally benign catalysts for base-catalyzed reactions. Replacement of the traditional homogeneous catalysts, such as aqueous $\mathrm{KOH}$, by heterogeneous catalysts could result in the reduction of waste streams, facile separation of the catalyst, and reusability of the catalyst. It has been shown that activated hydrotalcites can be used in several base-catalyzed liquid-phase reactions such as aldol-type condensations, Knoevenagel condensations, Michael additions, and Claisen-Schmidt condensations at ambient temperature with appreciable rates and selectivity. ${ }^{1-14}$ However, the nature of the active sites in activated hydrotalcites, which is the topic of this paper, has remained largely unknown.

HT or layered double hydroxide, e.g., $\mathrm{Mg}_{4} \mathrm{Al}_{2}(\mathrm{OH})_{12} \mathrm{CO}_{3}$. $4 \mathrm{H}_{2} \mathrm{O}$, has a structure similar to that of $\mathrm{Mg}(\mathrm{OH})_{2}$. In the latter, $\mathrm{Mg}^{2+}$ is octahedrally coordinated by hydroxyl groups, which are edge-shared to form a sheet-like structure. A net positive charge of the brucite-like layers originates from replacement of $\mathrm{Mg}^{2+}$ by $\mathrm{Al}^{3+}$. This charge is compensated for by anions, typically carbonate, situated together with water molecules in the interlayers. ${ }^{15} \mathrm{HT}$ intercalated with carbonate displays no catalytic activity in liquid-phase aldol condensation reactions. ${ }^{10,12}$ To obtain a highly active solid base catalyst, HT can be activated by replacement of $\mathrm{CO}_{3}{ }^{2-}$ by $\mathrm{OH}^{-}$, i.e., stronger Brønsted-base

* To whom correspondence should be addressed. Tel: +31-30-2536762. Fax: +31-30-2511027. E-mail: k.p.dejong@chem.uu.nl.

$\dagger$ Utrecht University.

$\doteqdot$ Ruhr-University Bochum. sites. $^{8-12}$ The generally applied method of activation is the thermal activation method. Thermal decomposition of HT in the temperature range of $723-773 \mathrm{~K}$ leads to the formation of a mixed oxide phase, $\mathrm{Mg}(\mathrm{Al}) \mathrm{O}$. In a next step the mixed oxide is rehydrated under $\mathrm{CO}_{2}$ free conditions, and the layered structure is recovered to a large extent with Brønsted-base sites $\left(\mathrm{OH}^{-}\right)$incorporated in the interlayer. ${ }^{8-12}$

Much research has been conducted on structure-activity relationships of activated HTs as solid base catalysts. Recently, it was found that the actual active sites are situated at the edges of the platelets, $5,6,9,10,12,16$ which is only a minor part of the Brønsted-base groups present. The number of edge sites could be enhanced by decreasing the lateral size of the HT crystallites..$^{9,12,16}$ Recently, we have reported that the linear correlation between the number of active sites (determined by titration with $\mathrm{CO}_{2}$ ) and the initial activity found in the condensation of acetone is viable over a wide range. ${ }^{12,16}$ It has been shown that the catalytic performance of activated HTs can be affected sub-

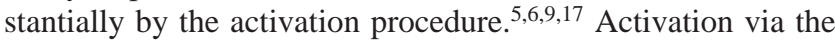
rehydration procedure results in a dramatic change in morphology of the platelets. A more irregular structure of the agglomerated platelets has been observed after reconstruction as compared to that of the catalyst precursors. ${ }^{5,6,9,18}$

Roelofs et al. ${ }^{9}$ reported that activation of HT involves both the introduction of $\mathrm{OH}^{-}$and a reconstruction of the HT platelets. Characterization of an activated HT prepared via aqueous ionexchange showed that the original HT structure can be largely preserved in contrast to samples activated via the rehydration route. The activity and the turn over frequency (TOF) in the condensation of acetone at $273 \mathrm{~K}$ of the samples obtained by 


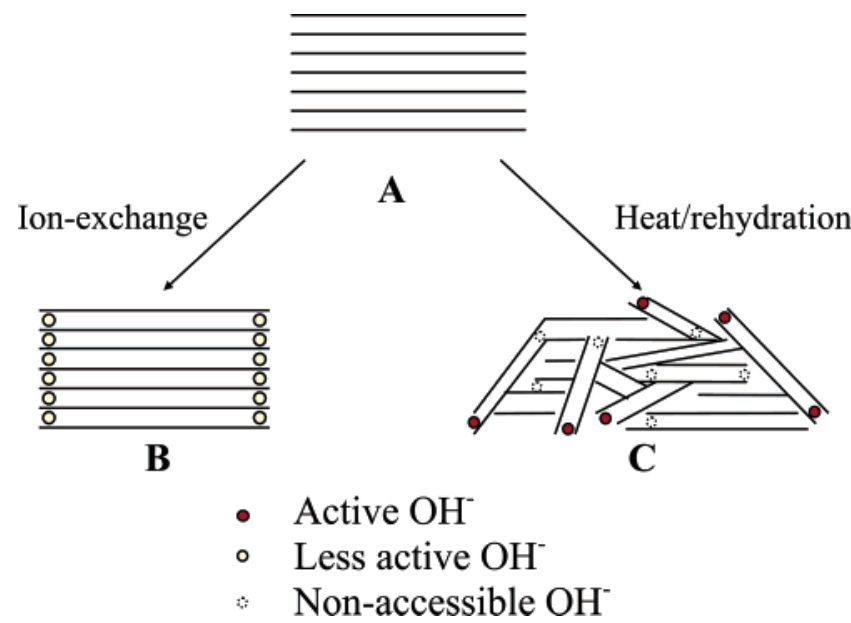

Figure 1. Schematic representation of the effect of the activation procedure on the HT structure, adapted from ref 9: (A) HT assynthesized; (B) HT after ion-exchange; (C) HT after heat treatment and rehydration.

the thermal activation route were much higher than with samples activated via ion-exchange methods. It was proposed that the enhanced catalytic performance is related to the more irregular structure, as schematically represented in Figure 1. Abelló et al. ${ }^{5,6}$ studied the rehydration of the mixed oxide via two rehydration procedures, i.e., in water vapor and in the liquid phase. Upon gas-phase reconstruction, a lower number of exposed active sites was found compared with samples reconstructed in the liquid phase, which was explained by a difference in accessibility of the obtained basic sites. However, the large difference in activity in the condensation of citral with acetone at $333 \mathrm{~K}$ can only be partly accounted for by the variance in number of basic sites, since the TOFs differed largely as well. The results of these studies suggest that the irregular structure obtained via rehydration gives rise to an increase in strength of the basic sites and/or an improved accessibility of the basic sites near the edges of the platelets. Further study on the nature and accessibility of the active sites is therefore necessary to understand and explain the large differences in catalytic activity.

To this end we have characterized in detail HT activated via the thermal route and HT activated via modified ion-exchange methods using, for instance, $\mathrm{XRD}, \mathrm{N}_{2}$ physisorption, $\mathrm{CO}_{2}$ chemisorption, and TEM. The catalytic properties of the activated HTs were investigated in the base-catalyzed selfcondensation of acetone to diacetone alcohol to establish structure-activity relationships. The strength and accessibility of the basic sites were assessed by calorimetry of $\mathrm{CO}_{2}$ adsorption and by IR spectroscopy of adsorbed $\mathrm{CDCl}_{3}$.

\section{Experimental Section}

Preparation of Hydrotalcites. HT with an $\mathrm{Mg} / \mathrm{Al}$ ratio of 2 was prepared via coprecipitation. ${ }^{13,19}$ To an aqueous solution (70 mL) containing $0.35 \mathrm{~mol} \mathrm{NaOH}$ (Merck) and $0.09 \mathrm{~mol}$ $\mathrm{Na}_{2} \mathrm{CO}_{3}$ (Acros) was added an aqueous solution $(45 \mathrm{~mL})$ of $0.1 \mathrm{~mol} \mathrm{Mg}\left(\mathrm{NO}_{3}\right)_{2} \cdot 6 \mathrm{H}_{2} \mathrm{O}$ (Acros) and $0.05 \mathrm{~mol} \mathrm{Al}\left(\mathrm{NO}_{3}\right)_{3} \cdot 9 \mathrm{H}_{2} \mathrm{O}$ (Merck). The resulting white suspension was heated to $333 \mathrm{~K}$ for $24 \mathrm{~h}$ under vigorous stirring, after which the precipitate was filtered off and washed extensively. The sample, further designated as HT-carb, was dried for $24 \mathrm{~h}$ at $393 \mathrm{~K}$.

HT with oxalate as the compensating anion was prepared via a method adapted from that of Titulaer. ${ }^{20}$ An aqueous solution (55 mL) containing $0.05 \mathrm{~mol} \mathrm{Al}\left(\mathrm{NO}_{3}\right)_{3} \cdot 9 \mathrm{H}_{2} \mathrm{O}$ (Merck) and 0.1 mol $\mathrm{Mg}\left(\mathrm{NO}_{3}\right)_{2} \cdot 6 \mathrm{H}_{2} \mathrm{O}$ (Acros) was added all at once to an aqueous solution $(160 \mathrm{~mL})$ containing $0.39 \mathrm{~mol} \mathrm{KOH}$ (Merck)
TABLE 1: Sample Names and Treatment Conditions of the Various Samples

\begin{tabular}{|c|c|c|}
\hline sample code & designation & comments \\
\hline HT-carb & as-synthesized & carbonate as interlayer anion \\
\hline HT-heat & $\mathrm{Mg}(\mathrm{Al}) \mathrm{O}$ & heat treated at $723 \mathrm{~K}$ \\
\hline HT-reh & activated & rehydration of HT-heat \\
\hline HT-оха & as-synthesized & oxalate as interlayer anion \\
\hline HT-exc & activated & $\begin{array}{l}\text { ion-exchange of HT-oxa in aq KOH } \\
\text { at } 349 \mathrm{~K}\end{array}$ \\
\hline HT-exr & activated & ibid. at $\sim 373 \mathrm{~K}$ (boiling) \\
\hline HT-e & activated & $\begin{array}{l}\text { ibid. at } \sim 323 \mathrm{~K} \text { under ultrasonic } \\
\text { treatment }\end{array}$ \\
\hline $\mathrm{Mg}(\mathrm{OH})_{2}$ & as-synthesized & precipitated at $333 \mathrm{~K}$ \\
\hline $\mathrm{Mg}(\mathrm{OH})_{2^{-}}$ & activated & $\begin{array}{l}\mathrm{Mg}(\mathrm{OH})_{2} \text { after heat treatment and } \\
\text { rehydration }\end{array}$ \\
\hline
\end{tabular}

and $0.016 \mathrm{~mol}$ oxalic acid (Merck) under nitrogen atmosphere. To remove $\mathrm{CO}_{2}$ from the solution, the solutions had been previously outgassed. The resulting white suspension was stirred at $293 \mathrm{~K}$ for $1 \mathrm{~h}$, after which a third aqueous solution $(70 \mathrm{~mL})$ of $0.052 \mathrm{~mol}$ oxalic acid and $0.11 \mathrm{~mol} \mathrm{KOH}$ was added. The suspension was heated at $367 \mathrm{~K}$ under vigorously stirring for $20 \mathrm{~h}$ under $\mathrm{N}_{2}$ atmosphere, after which the precipitate was filtered off and washed extensively. The sample, further designated as HT-oxa, was dried in nitrogen flow at $333 \mathrm{~K}$ for $24 \mathrm{~h}$.

Activation of the Catalyst Precursors. The descriptions of the various materials together with the identification codes are listed in Table 1. HT-carb was activated by heating in a nitrogen flow to $723 \mathrm{~K}\left(10 \mathrm{~K} \mathrm{~min}^{-1}\right)$ for $8 \mathrm{~h}$ and allowed to cool to room temperature (HT-heat). ${ }^{8,9}$ HT-heat was rehydrated in decarbonated water and stirred under $\mathrm{N}_{2}$ atmosphere for $1 \mathrm{~h}$. Next, the sample was filtered off and dried in $\mathrm{N}_{2}$ flow at 293 $\mathrm{K}$. The sample is further denoted as HT-reh.

For the activation via aqueous ion-exchange HT-oxa was used as precursor material, since oxalate can be readily exchanged for $\mathrm{OH}^{-} .9,15,21,22$ To a decarbonated $0.5 \mathrm{M} \mathrm{KOH}$ solution (200 $\mathrm{mL}$ ) was added $1.6 \mathrm{~g}$ of HT-oxa. The suspension was heated to $349 \mathrm{~K}$ and stirred at that temperature for $20 \mathrm{~h}$ under nitrogen atmosphere. At room temperature, the resulting precipitate was filtered off, washed extensively, and dried in $\mathrm{N}_{2}$ flow at $293 \mathrm{~K}$ (HT-exc). A second sample was activated by ion-exchange under reflux conditions by performing the activation in boiling $0.5 \mathrm{M}$ $\mathrm{KOH}$ solution under ambient pressure (HT-exr). Finally, a Branson sonifier W450 was used at $90 \%$ for the ion-exchange performed under ultrasonic treatment for $1 \mathrm{~h}$ (HT-exu) at 323 $\mathrm{K}$. The stainless steel ultrasonic tip was immerged in the suspension.

$\mathrm{Mg}(\mathrm{OH})_{2}$ was prepared by adding an aqueous solution (50 $\mathrm{mL}$ ) containing $0.1 \mathrm{~mol} \mathrm{Mg}\left(\mathrm{NO}_{3}\right) \cdot 6 \mathrm{H}_{2} \mathrm{O}$ to an aqueous solution (200 mL) containing $0.3 \mathrm{~mol} \mathrm{KOH}$. The resulting white suspension was heated to $333 \mathrm{~K}$ for $24 \mathrm{~h}$ under vigorous stirring, after which the precipitate was filtered off and washed extensively. The sample, further designated as $\mathrm{Mg}(\mathrm{OH})_{2}$, was dried for $24 \mathrm{~h}$ at $393 \mathrm{~K} . \mathrm{Mg}(\mathrm{OH})_{2}$ was activated via the heat treatment rehydration procedure as described above. This sample is further denoted as $\mathrm{Mg}(\mathrm{OH})_{2}$-reh.

Catalyst Characterization. Powder X-ray diffraction (XRD) patterns were measured using an Enraf-Nonius CPS 120 powder diffraction apparatus with $\mathrm{Co} \mathrm{K} \alpha$ radiation $(\lambda=1.789 \AA)$. Volumetric $\mathrm{CO}_{2}$ adsorption measurements in the range of $0-50$ mbar were executed at $273 \mathrm{~K}$ with a Micromeritics ASAP $2010 \mathrm{C}$ apparatus after drying the samples at $393 \mathrm{~K}$ in a vacuum for at least $20 \mathrm{~h}$. After evacuation of the sample, $\mathrm{CO}_{2}$ was dosed with small increments. The total number of basic sites was determined taking the amount of $\mathrm{CO}_{2}$ chemisorbed at zero 
pressure obtained by extrapolation of the linear part of the uptake isotherm. ${ }^{8-10,12,23} \mathrm{~N}_{2}$ physisorption measurements were performed using a Micromeritics Tristar 3000 analyzer after drying the samples at $393 \mathrm{~K}$ for at least $20 \mathrm{~h}$. TEM images were obtained with a Fei Technai 20 FEG TEM operating at 200 $\mathrm{kV}$. Samples were, after ultrasonic treatment, dispersed on a holey carbon film supported on a copper grid. To study the exchange of oxalate, FTIR spectra of HT were recorded from 400 to $4000 \mathrm{~cm}^{-1}$ with a Perkin-Elmer 2000 Fourier transform spectrometer equipped with a DTGS detector using the $\mathrm{KBr}$ pellet technique.

Calorimetric Study of $\mathbf{C O}_{2}$ Adsorption. Prior to the microcalorimetric measurements, $0.1 \mathrm{~g}$ of activated HT (sieve fraction between 212 and $425 \mu \mathrm{m}$ ) was dried in a vacuum at $393 \mathrm{~K}$ for $20 \mathrm{~h}$. Contact with air during the preparation of the samples was avoided by working in nitrogen atmosphere in a glovebox. The dried samples were transferred to the calorimetric setup in a glass capsule, sealed under vacuum. Adsorption of $\mathrm{CO}_{2}$ was followed by calorimetry using a specially designed measurement cell in a Tian-Calvet calorimeter as described elsewhere. ${ }^{24}$ The apparent leak rate of the dosing apparatus was about $3 \times 10^{-4} \mathrm{~Pa} \mathrm{~s}^{-1}$. After degassing the setup at $393 \mathrm{~K}$, the temperature was lowered to $303 \mathrm{~K}$. The capsule was crushed in the measuring cell by a linear motion feed-through after which the cell was filled with nitrogen $\left(P_{\mathrm{N}_{2}}=60 \mathrm{~Pa}\right)$. To measure the differential heat of adsorption, $\mathrm{CO}_{2}$ was dosed sequentially at $303 \mathrm{~K}$ with small increments up to a pressure of $80 \mathrm{~Pa}$. The differential heat of adsorption was calculated for each dose by dividing the measured heat produced by the quantity of adsorbed $\mathrm{CO}_{2}$ of each dose.

Diffuse Reflectance Infrared Fourier Transformed Spectroscopy of $\mathbf{C D C l}_{3}$ Adsorption. During $\mathrm{CDCl}_{3}$ adsorption, DRIFT spectra were recorded on a Perkin-Elmer Spectrum One instrument with an MCT detector. A Harrick Praying Mantis DRIFT cell with a high-temperature reaction chamber with $\mathrm{CaF}_{2}$ windows was used for the adsorption measurements. The sample (nondiluted) was placed in the sampling cup on the Praying Mantis and heated to $493 \mathrm{~K}$ for $2 \mathrm{~h}$ in a stream of helium (10 $\left.\mathrm{mL} \min ^{-1}\right)$. Subsequently, the sample was cooled to $303 \mathrm{~K}$, and the adsorption of $\mathrm{CDCl}_{3}$ (Acros) was started by switching the gas stream at atmospheric pressure to $\mathrm{CDCl}_{3}$ in $\mathrm{He}$ flow $\left(10 \mathrm{~mL} \mathrm{~min}^{-1}\right)\left(P_{\mathrm{CDCl}_{3}} / P_{\text {total }}=0.2\right)$. Spectra were measured with a resolution of $4 \mathrm{~cm}^{-1}$ (250 scans) with the spectrum of the HT sample (after drying) as the background.

Catalytic Tests. The self-condensation of acetone was performed under $\mathrm{N}_{2}$ atmosphere in a stirred double-walled thermostatically cooled glass reactor, equipped with baffles. Typically, $1.8 \mathrm{~mol}$ of acetone (Merck) was cooled to $273 \mathrm{~K}$, and $0.3 \mathrm{~g}$ of activated HT catalyst was added under $\mathrm{N}_{2}$ flow to exclude atmospheric $\mathrm{CO}_{2}$. Aliquots of $1 \mathrm{~mL}$ were taken from the reaction mixture during reaction and analyzed using a Chrompack CP 9001 GC provided with a Chrompack CP 9050 autosampler. Isooctane (Acros) was used as an internal standard to calculate the amount of diacetone alcohol (DAA) formed.

\section{Results and Discussion}

Catalyst Characterization. In Figure 2 the XRD patterns of the various hydrotalcite compounds are given. The pattern of HT-carb showed the diffraction lines typical for a hydrotalcite compound with interlayer carbonate. ${ }^{15}$ Heat treatment up to 723 $\mathrm{K}$ resulted in the destruction of the layered compound and the formation of a mixed oxide, $\mathrm{Mg}(\mathrm{Al}) \mathrm{O}$, with diffraction lines at values similar to that of $\mathrm{MgO}$. By rehydration of the mixed oxide the HT structure is restored to a large extent as can be

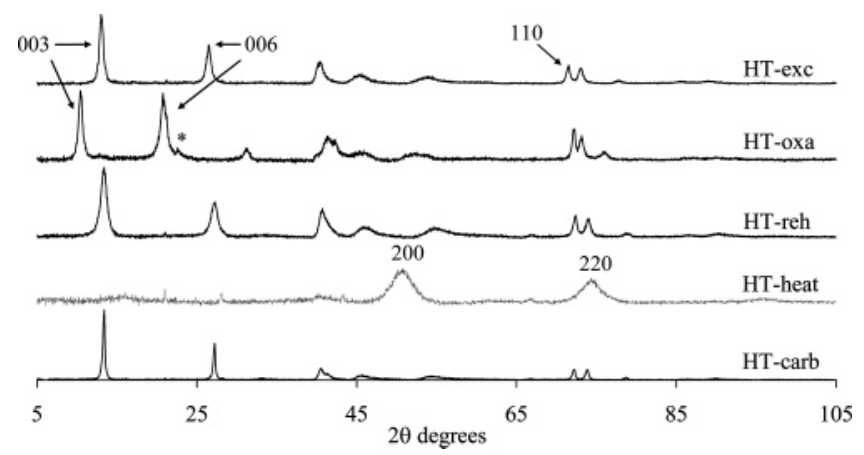

Figure 2. X-ray diffraction patterns of HT with interlayer carbonate (HT-carb); after heat treatment at $723 \mathrm{~K}$ (HT-heat); after heat treatment and rehydration (HT-reh); HT with interlayer oxalate (HT-oxa); after aqueous ion-exchange in $\mathrm{KOH}$ solution (HT-exc).

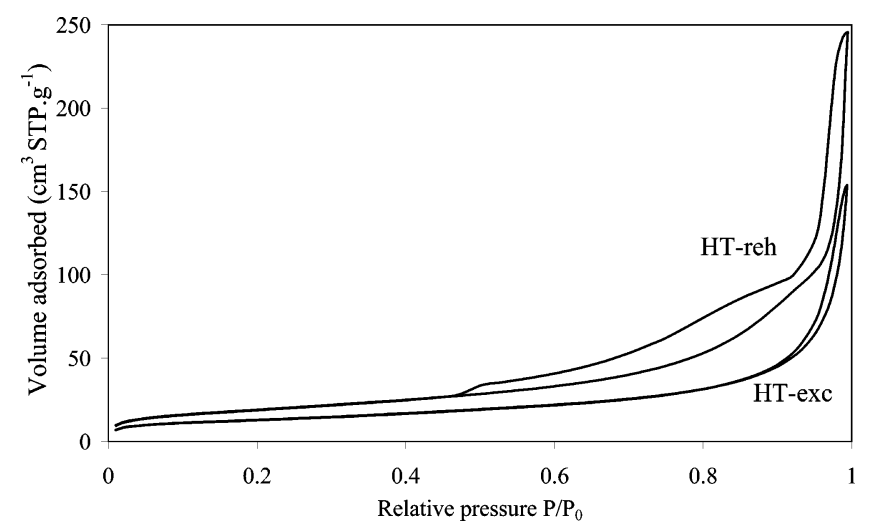

Figure 3. $\mathrm{N}_{2}$ adsorption and desorption isotherms of HT-exc and HTreh.

concluded from the XRD pattern of HT-reh, although the line broadening indicates a loss in crystallinity compared to HTcarb. By exclusion of other anions and $\mathrm{CO}_{2}$, Brønsted-base sites $\left(\mathrm{OH}^{-}\right)$are incorporated in HT-reh. The pattern of HT-oxa is similar to that reported in the literature. ${ }^{9,20}$ The shift of the $(00 l)$ reflections in the HT-oxa pattern toward lower $2 \theta$ values is explained by the presence of oxalate as the compensating anion. From the position of the $(00 l)$ reflections, the lattice distance can be calculated (the sum of one brucite-like layer and one interlayer spacing), which is dependent on the nature of the compensating anion present and the degree of hydration, ${ }^{15}$ i.e., $7.7 \AA$ for HT-carb/HT-reh and $9.8 \AA$ for HToxa. The diffraction line at $22.6^{\circ} 2 \theta$ in the HT-oxa pattern (indicated with an asterisk in Figure 2) was observed earlier and is ascribed to a superlattice diffraction likely coming from a high degree of cation ordening. ${ }^{9}$ The shift of the (003) line from $9.8 \AA\left(2 \theta=10.8^{\circ}\right)$ to $7.8 \AA\left(2 \theta=13.2^{\circ}\right)$ in the pattern of HT-exc compared with that of HT-oxa indicates that oxalate has been successfully replaced with $\mathrm{OH}^{-}$upon ionexchange.

$\mathrm{N}_{2}$ physisorption experiments were performed to obtain texture information of the different HT materials. In Figure 3, the $\mathrm{N}_{2}$ adsorption and desorption isotherms of HT-reh and HTexc are given. The hysteresis between 0.47 and $0.8 P / P_{0}$ in the isotherms of HT-reh indicates an enhanced mesoporosity of HTreh as compared to HT-exc. The pore size distribution as given in Figure 4 shows that smaller mesopores $(5-20 \mathrm{~nm})$ are formed in HT-reh, which are hardly present in HT-exc. The results from $\mathrm{N}_{2}$ physisorption of the HTs as-synthesized and those of HTs after activation are summarized in Table 2. Upon heat treatment of HT-carb, the specific surface area increases significantly as well as the micropore and mesopore volume due to dehydroxyl- 


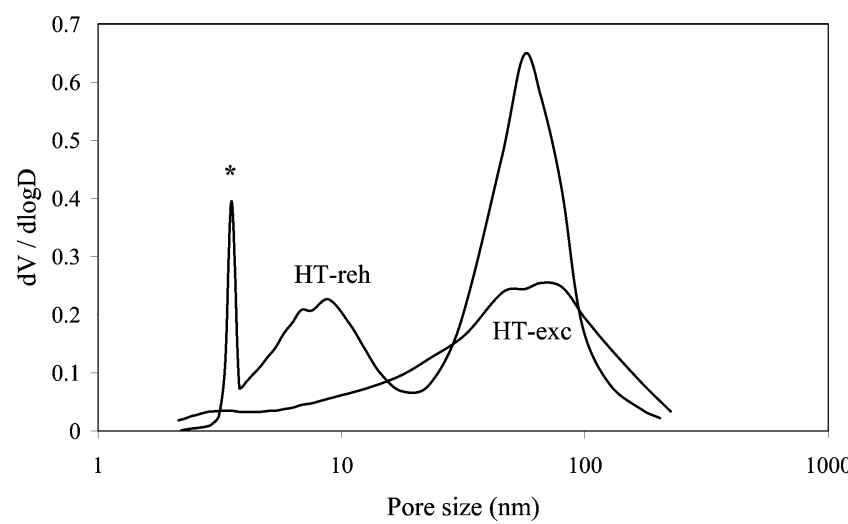

Figure 4. Pore size distributions of HT-exc and HT-reh calculated from the desorption branch using the BJH method. *Artifact of the BJH model.

TABLE 2: Results from $\mathbf{N}_{2}$ Physisorption Measurements and from ICP

\begin{tabular}{lccccc}
\hline sample & $\begin{array}{c}S_{\mathrm{BET}^{a}} \\
\left(\mathrm{~m}^{2} \mathrm{~g}^{-1}\right)\end{array}$ & $\begin{array}{c}S_{t}^{b} \\
\left(\mathrm{~m}^{2} \mathrm{~g}^{-1}\right)\end{array}$ & $\begin{array}{c}\text { total pore } \\
\text { volume } \\
\left(\mathrm{cm}^{3} \mathrm{~g}^{-1}\right)\end{array}$ & $\begin{array}{c}\text { micropore } \\
\text { volume } \\
\left(\mathrm{cm}^{3} \mathrm{~g}^{-1}\right)\end{array}$ & $\mathrm{Mg} / \mathrm{Al}^{c}$ \\
\hline HT-carb & 89 & 87 & 0.74 & 0.00 & 2.2 \\
HT-heat & 191 & 163 & 0.97 & 0.01 & n.d. $^{d}$ \\
HT-reh & 69 & 67 & 0.38 & 0.00 & 2.2 \\
HT-oxa & 47 & 46 & 0.24 & 0.00 & 2.1 \\
HT-exc & 46 & 45 & 0.24 & 0.00 & 2.2 \\
HT-exr & 89 & 87 & 0.48 & 0.00 & 2.2
\end{tabular}

${ }^{a}$ BET method. ${ }^{b} t$-method. ${ }^{c}$ ICP analysis. ${ }^{d}$ n.d. $=$ not determined.

ation and decomposition of interlayer carbonate. ${ }^{25,26}$ Upon reconstructing the HT structure, the micropores disappear and the surface area and pore volume decrease. Following calcination and rehydration, the HT platelets are packed more closely together as is also apparent from the TEM data (Figure 5). Consequently, the total pore volume dropped but the mesoporosity increased. HT-exc exhibits a surface area and pore volume similar to that of HT-oxa, indicating that except for the exchange of oxalate by $\mathrm{OH}^{-}$, as was concluded based on XRD results, no significant changes in texture of the material are apparent.

Volumetric $\mathrm{CO}_{2}$ adsorption measurements at low pressures were performed to determine the total amount of accessible Brønsted-base sites present in the activated HTs (Table 3). On the basis of the number of $\mathrm{Al}^{3+}$ ions as established by ICP analysis and the results from $\mathrm{CO}_{2}$ adsorption, it is demonstrated that only a minor part (up to $10 \%$ ) of the $\mathrm{OH}^{-}$ions present in the activated HT samples is titrated with $\mathrm{CO}_{2}$ at low pressure, which is consistent with the model that $\mathrm{CO}_{2}$ uptake is confined to $\mathrm{OH}^{-}$ions present at or near the edges of the platelets. ${ }^{9,12} \mathrm{~A}$ large difference between the adsorbed amount of $\mathrm{CO}_{2}$ between by HT-reh and HT-exc is observed, 0.16 versus $0.44 \mathrm{mmol}$ $\mathrm{g}_{\text {cat }}{ }^{-1}$. Calculation of the exposed edge area in HT-exc based on the hexagonal platelet structure indicates that the amount of $\mathrm{CO}_{2}$ adsorbed correlates rather well with the edge area. The relatively low amount of $\mathrm{CO}_{2}$ adsorbed on HT-reh, in agreement with the data reported in the literature, ${ }^{6,8,9,18}$ is ascribed to agglomeration of HT platelets brought about by the activation method, making the edge sites within the agglomerates inaccessible as schematically represented in Figure 1C.

Figure 5 shows TEM images of the as-synthesized and the activated HTs. The TEM image of HT-reh shows the effect of activation via heat treatment and rehydration on the morphology of the material. The hexagonal platelets as found with the assynthesized materials (Figure 5A) have been transformed into an irregular structure (Figure 5B), although the HT phase is clearly present in the XRD pattern of HT-reh. The increase in pore volume of mesopores between 5 and $20 \mathrm{~nm}$ and the decrease of the total pore volume (Table 2) in the $\mathrm{N}_{2}$ physisorption experiments further indicate the more close packing of irregularly shaped platelets (Table 2, Figure 4). Results obtained from TEM analysis of HT-exc show that the original hexagonal structure of HT-oxa is preserved upon ion-exchange (Figure 5C,D).

Catalytic Performance. The catalytic properties of the catalysts were investigated in the self-condensation of acetone to diacetone alcohol (DAA) at $273 \mathrm{~K}$. The catalytic properties of HT-reh and HT-exc are given in Table 3 and Figure 6. The as-synthesized materials did not exhibit catalytic activity. HTheat displayed some condensation activity comparable to what is reported by other authors, ${ }^{6,10,18}$ i.e., $26 \mathrm{mmol}_{\text {DAA }} \mathrm{g}_{\text {cat }}{ }^{-1} \mathrm{~h}^{-1}$. HT-reh displayed a much higher activity than HT-heat, which stresses that Brønsted-base sites are mandatory to obtain a high catalytic activity. ${ }^{7-9}$ The initial activity of HT-reh in relation to the number of active sites as determined by volumetric $\mathrm{CO}_{2}$ adsorption corresponds well with the correlation reported earlier between the number of edge sites and the activity in the condensation of acetone over activated HTs with different platelet sizes. ${ }^{9,12}$ The activity of HT-exc was low, that is, 12 mmol $_{\text {DAA }} \mathrm{g}_{\text {cat }}{ }^{-1} \mathrm{~h}^{-1}$, comparable to what has been reported earlier. ${ }^{9}$ On the basis of the correlation between the number of edge sites and the initial activity, we would expect an activity of $337 \mathrm{mmol}_{\text {DAA }} \mathrm{g}_{\mathrm{cat}}{ }^{-1} \mathrm{~h}^{-1}$ with the exchanged sample. For sake of argument, brucite $\left(\mathrm{Mg}(\mathrm{OH})_{2}\right)$ was investigated in the condensation of acetone at $273 \mathrm{~K}$ too. The as-synthesized material, $\mathrm{Mg}(\mathrm{OH})_{2}$, as well as $\mathrm{Mg}(\mathrm{OH})_{2}$-reh (activated via the heat treatment and rehydration procedure) did not exhibit any condensation activity (Table 3 ). These results rule out structural $\mathrm{OH}$ groups to be the active sites. However, we do not exclude some involvement of structural $\mathrm{OH}$ groups in the catalytic mechanism. ${ }^{27,28}$

Evaluation of Basic Strength and Accessibility of Active Sites. Calorimetric Study of $\mathrm{CO}_{2}$ Adsorption. To gain information about the strength of the basic sites calorimetric measurements were performed by determining the heat of adsorption of $\mathrm{CO}_{2}$ on the activated HTs. Earlier calorimetric studies using carbon dioxide as a probe molecule showed that an estimation of base strength can be obtained with the heat of adsorption up to $160 \mathrm{~kJ} \mathrm{~mol}^{-1} \cdot{ }^{8,23,29-36}$ Figure 7 displays the differential heat of adsorption in the range of $0-50 \mu \mathrm{mol}_{\mathrm{CO}_{2}} \mathrm{~g}_{\mathrm{HT}}{ }^{-1}$. An initial heat of adsorption of $100-110 \mathrm{~kJ} \mathrm{~mol}^{-1}$ is observed that dropped below $80 \mathrm{~kJ} \mathrm{~mol}^{-1}$ already at relatively low uptake. Sanchez Valente et al. ${ }^{23}$ investigated the heat of adsorption of $\mathrm{CO}_{2}$ using calorimetry on various hydrotalcite-like materials. They measured small but significant differences in basic strength by changing the chemical composition of the hydrotalcite $\left(\mathrm{Al}^{3+}\right.$ for $\mathrm{Fe}^{3+}$ or $\mathrm{Cr}^{3+}$ ). The heat of adsorption at low uptake of our samples (Table 3) is similar to those reported by Figueras and co-workers. ${ }^{8,23}$ Although the initial heats of adsorption of HTexc and HT-reh are similar, a higher number of basic sites with a heat of adsorption above $80 \mathrm{~kJ} \mathrm{~mol}^{-1}$ was found for the exchanged sample. On the basis of these results we would expect HT-exc to exhibit a catalytic activity above that obtained for HT-reh.

During the calorimetric measurements with both types of samples we observed at an uptake above $40 \mu \mathrm{mol} \mathrm{g}_{\mathrm{HT}}{ }^{-1}$ an endothermic process when $\mathrm{CO}_{2}$ had been dosed (Figure 8). At low uptake a continuous drop of pressure coincided with an exothermic process (Figure 8A), whereas at high uptake an 

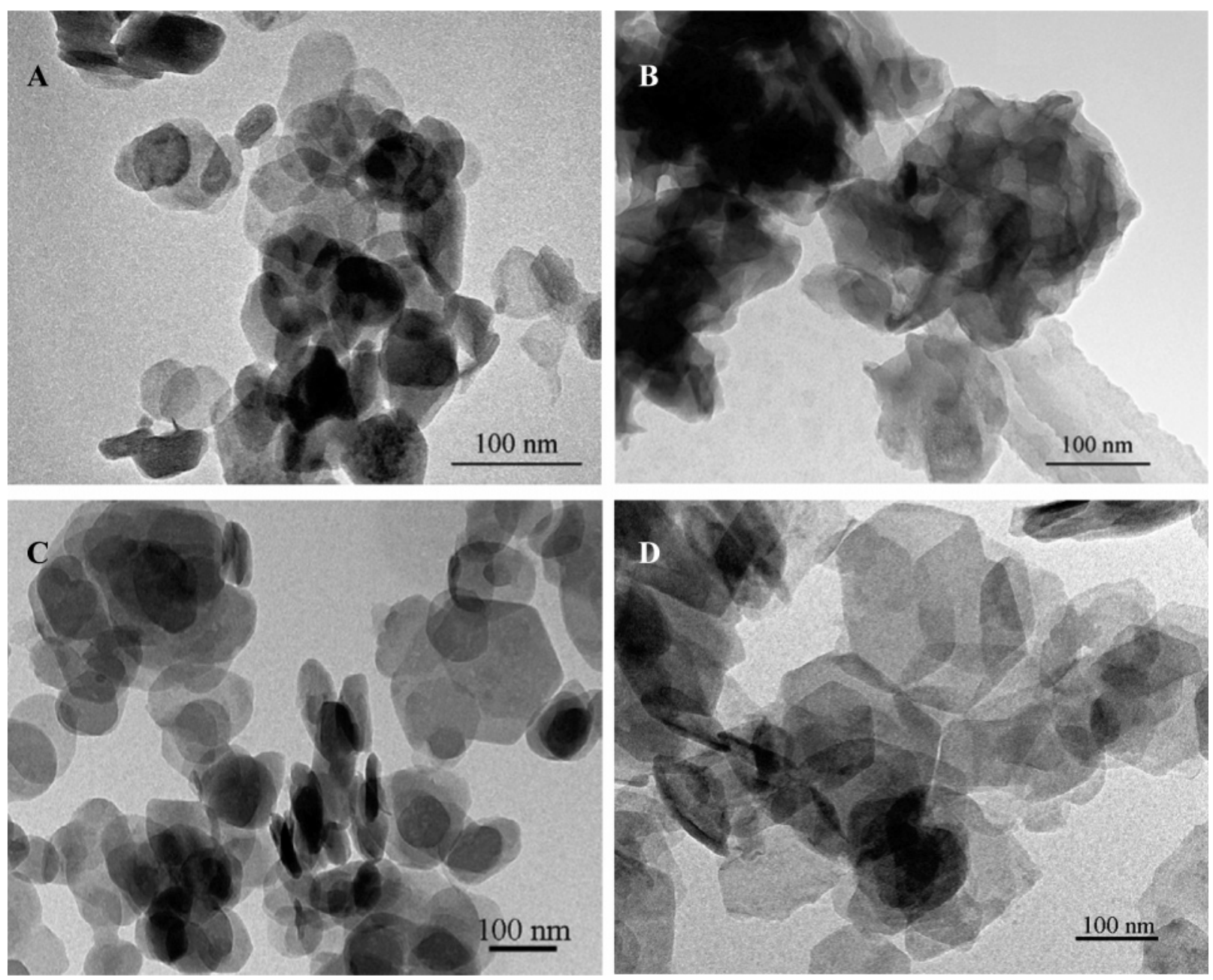

Figure 5. TEM images of (A) HT-carb, (B) HT-reh, (C) HT-oxa, and (D) HT-exc.

TABLE 3: Results from $\mathrm{CO}_{2}$ Adsorption and Catalytic Measurements

\begin{tabular}{lcccc}
\hline \multicolumn{1}{c}{ sample } & $\begin{array}{c}\mathrm{CO}_{2} \\
\text { adsorption }^{a} \\
\left(\text { mmol g }_{\mathrm{HT}^{-1}}\right)^{-1}\end{array}$ & $\begin{array}{c}\text { initial activity } \\
\left(\mathrm{mmol}_{\text {DAA }} \mathrm{g}_{\mathrm{HT}}{ }^{-1} \mathrm{~h}^{-1}\right)\end{array}$ & $\begin{array}{c}\mathrm{TOF} \\
\left(\mathrm{s}^{-1}\right)^{b}\end{array}$ & $\begin{array}{c}\text { initial heat } \\
\text { of adsorption } \\
\text { of } \mathrm{CO}_{2} \\
\left(\mathrm{~kJ} \mathrm{~mol}^{-1}\right)\end{array}$ \\
\hline HT-oxa & n.d. & 0 & n.d. & n.d. \\
HR-carb & n.d. & 0 & n.d. & n.d. \\
HT-heat & n.d. & 26 & n.d. & n.d. \\
HT-reh & 0.16 & 134 & 0.46 & 108 \\
HT-exc & 0.44 & 12 & 0.015 & 109 \\
HT-exr & 0.40 & 72 & 0.10 & 107 \\
$\operatorname{Mg}(\mathrm{OH})_{2}$-reh & n.d. & 0 & n.d. & n.d.
\end{tabular}

${ }^{a}$ From volumetric $\mathrm{CO}_{2}$ adsorption measurements. ${ }^{b}$ Turn-over frequency of acetone condensation based on the number of sites from $\mathrm{CO}_{2}$ adsorption. ${ }^{c}$ n.d. $=$ not determined.

endothermic peak overlapped with an exothermic peak coming from the heat evolution from $\mathrm{CO}_{2}$ adsorption (Figure 8B). Directly after dosing $\mathrm{CO}_{2}$ at an uptake above $40 \mu \mathrm{mol} \mathrm{\textrm {g } _ { \mathrm { HT } }}{ }^{-1}$ the pressure dropped rapidly due to adsorption of $\mathrm{CO}_{2}$ after which the pressure slowly increased and steady state was apparent after $20 \mathrm{~min}$. We suggest that both the increase in pressure after $2 \mathrm{~min}$ and the endothermic process originate from a time-delayed rearrangement of the HT structure, ${ }^{37}$ due to changes in composition of the interlayer (formation of bicarbonate, carbonate, and water) or stacking of the layers.

DRIFTS Study of $\mathrm{CDCl}_{3}$ Adsorption. To use FTIR as an accurate method for studying the basic properties of a catalyst the choice of the probe molecule is essential. Since $\mathrm{CO}_{2}$ is a

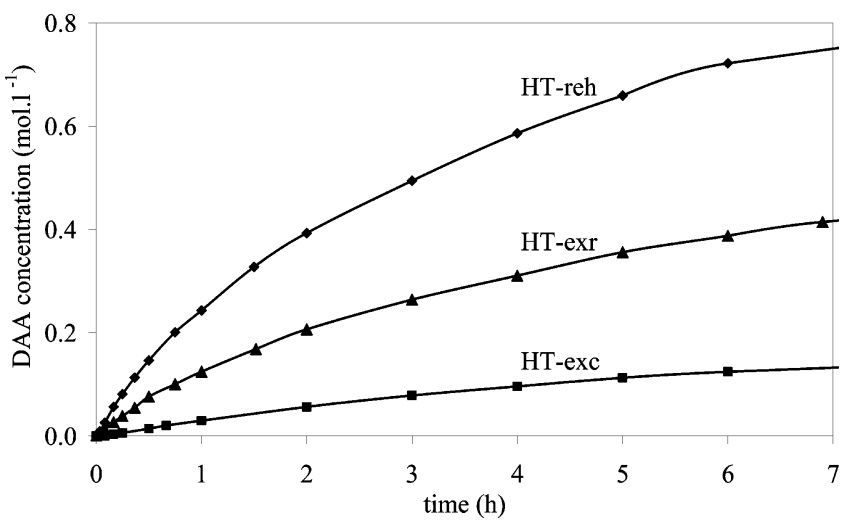

Figure 6. DAA formation in time for the self-condensation of acetone at $273 \mathrm{~K}$ over HT-reh, HT-exc, and HT-exr. A total of $1.8 \mathrm{~mol}$ acetone and $0.3 \mathrm{~g}$ of catalyst were initially present.

relatively strong acid which can easily react with $\mathrm{OH}^{-}$to bicarbonate and carbonate species, ${ }^{38-41}$ a weak acid as molecular probe seems more suitable. For reviews on IR spectroscopy of small and weakly interacting molecular probes, see refs 40, 4244. Paukshtis et al. ${ }^{45,46}$ have reported that $\mathrm{CDCl}_{3}$ can be used as a probe molecule to characterize the different types and strengths of basic sites. The main advantages of using deuterated chloroform as probe molecule $e^{45-57}$ are that it does not undergo chemical transformation under ambient conditions and that the relevant $v_{\mathrm{CD}}$ bands do not overlap with the bands of the $\mathrm{OH}$ groups. Furthermore, the size of this probe molecule is similar to that of acetone. 


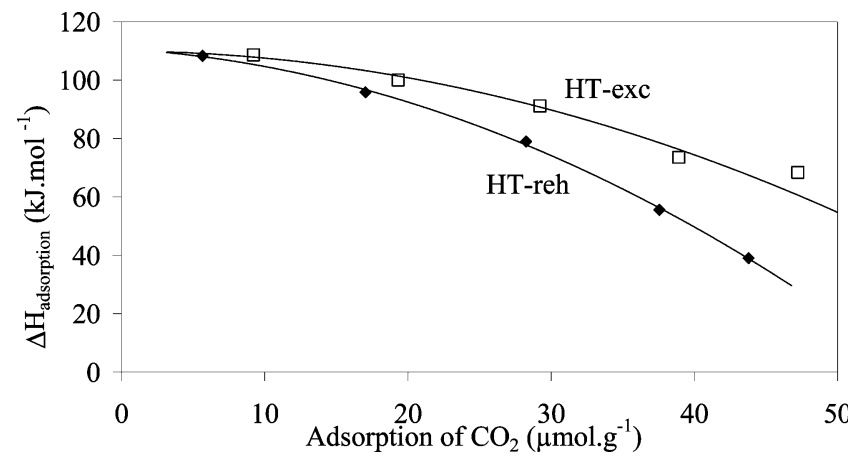

Figure 7. Differential heats of adsorption of $\mathrm{CO}_{2}$ on HT-reh and HTexc at $303 \mathrm{~K}$.
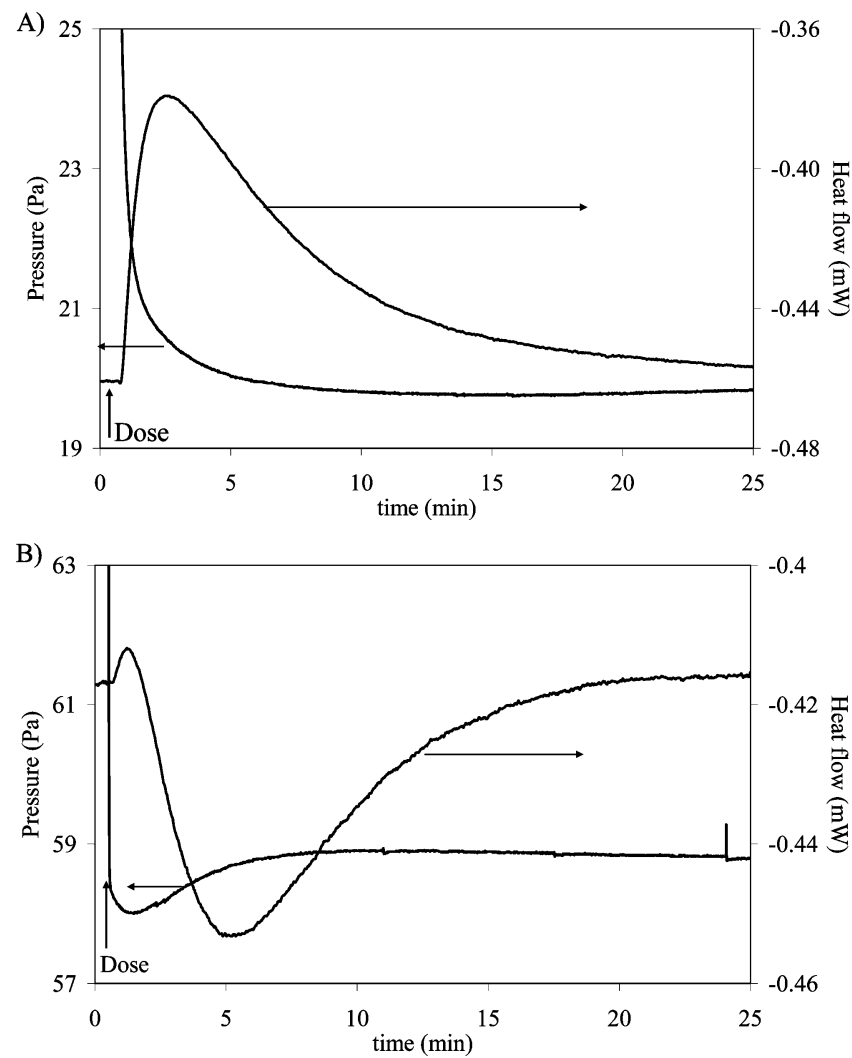

Figure 8. Examples of the heat evolution and pressure in time during calorimetry measurements of $\mathrm{CO}_{2}$ adsorption: (A) uptake below 40 $\mu \mathrm{mol}_{\mathrm{CO}_{2}} \mathrm{~g}^{-1}$; (B) uptake above $40 \mu \mathrm{mol}_{\mathrm{CO}_{2}} \mathrm{~g}^{-1}$.

$\mathrm{CDCl}_{3}$ displays an isolated $\mathrm{C}-\mathrm{D}$ stretching vibration $\left(\left[v_{\mathrm{CD}}\right]_{\text {gas }}\right.$ $=2264 \mathrm{~cm}^{-1}$ ), which is expected to shift to lower frequencies when it undergoes hydrogen bonding. Figure 9 shows the DRIFT spectra in the $v_{\mathrm{CD}}$ region $\left(2280-2120 \mathrm{~cm}^{-1}\right)$ of $\mathrm{CDCl}_{3}$ adsorbed on HT-carb, HT-exc, and HT-reh at $303 \mathrm{~K}$. The spectrum of adsorbed $\mathrm{CDCl}_{3}$ on $\mathrm{HT}$-carb is given to check whether the brucite-like layers adsorb $\mathrm{CDCl}_{3}$ strongly, which is not the case as can be concluded from Figure 9. Two bands at 2252 and $2238 \mathrm{~cm}^{-1}$ appeared with a very low intensity. It is likely that these bands originate from an interaction with interlayer carbonate, since an excess of brucite-like layers enables much more intense bands. The spectra of $\mathrm{CDCl}_{3}$ adsorbed on HT-reh and HT-exc show a relatively strong band at around $2221 \mathrm{~cm}^{-1}$. Deconvolution of the spectra of HT-exc and HT-reh revealed two more weak bands at 2249 and $2240 \mathrm{~cm}^{-1}$ (see inset Figure 9). The peak at $\sim 2220 \mathrm{~cm}^{-1}$ is assigned to an interaction with interlayer $\mathrm{OH}^{-}$. The position of the $v_{\mathrm{CD}}$ band in the spectrum of HT-reh and that of HT-exc do not show remarkable differences. However, a pronounced difference of intensities

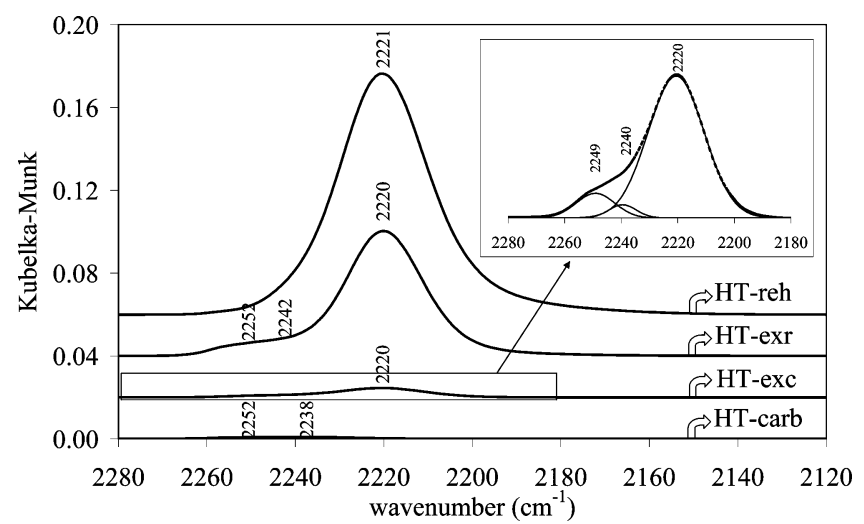

Figure 9. Background-subtracted DRIFT spectra $\left(v_{\mathrm{CD}}\right.$ region, HT used as background) of $\mathrm{CDCl}_{3}$ adsorbed on HT-carb, HT-exc, HT-exr, and HT-reh. For clarity reasons, the spectrum of HT-exc, HT-exr, and HTreh have been shifted vertically by $0.02,0.04$, and 0.06 , respectively. Inset shows the deconvolution of the $2280-2180 \mathrm{~cm}^{-1}$ region of the HT-exc spectrum.

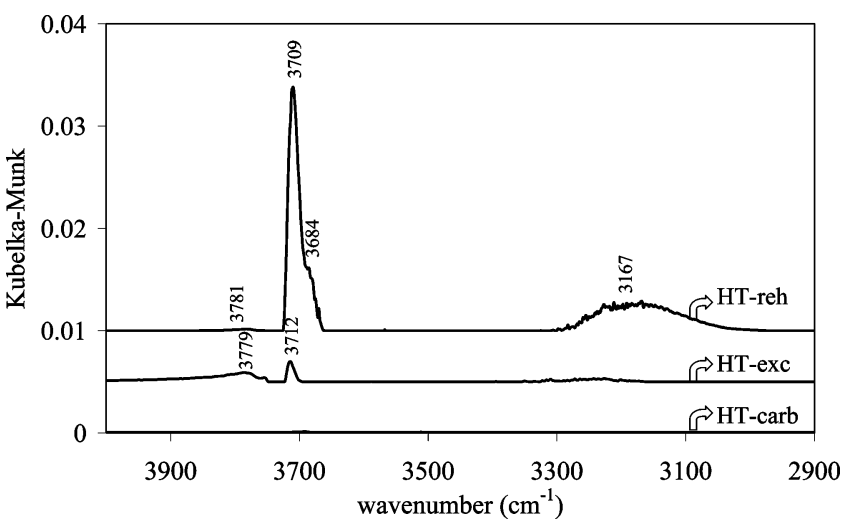

Figure 10. Background-subtracted DRIFT spectra $\left(v_{\mathrm{OH}}\right.$ region, HT used as background) of $\mathrm{CDCl}_{3}$ adsorbed on HT-carb, HT-exc, and HTreh. For clarity reasons, the spectrum of HT-exc and HT-reh have been shifted vertically by 0.005 and 0.01 , respectively.

\section{SCHEME 1: Different modes of interaction of $\mathrm{CDCl}_{3}$ with active sites}<smiles>ClC1(Cl)[CH][CH]O1</smiles>

A

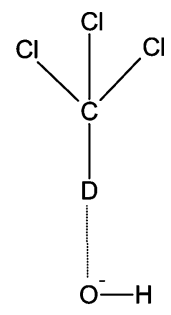

B shows that much more $\mathrm{CDCl}_{3}$ is adsorbed on HT-reh than on HT-exc. Evaluation of the shift in the $v_{\mathrm{CD}}$ band upon adsorption of $\mathrm{CDCl}_{3}$ reveals that the basic sites in HT-exc and HT-reh exhibit moderately basic strength. ${ }^{45-57}$

An interaction of $\mathrm{CDCl}_{3}$ with $\mathrm{OH}^{-}$also brings about new bands in the $v_{\mathrm{OH}}$ region (Figure 10). The absence of any additional bands in the HT-carb spectrum supports the supposition that no interaction of $\mathrm{CDCl}_{3}$ with the brucite-like layers is apparent. In the spectrum of HT-reh and HT-exc several bands appeared. The presence of these bands indicates that part of the $\mathrm{OH}^{-}$groups interact with deuterated chloroform upon adsorption. Note the difference in intensity of these bands with HT-reh and HT-exc, which is in line with the observation in the $v_{\mathrm{CD}}$ region. The appearance of these bands in the 3800$3650 \mathrm{~cm}^{-1}$ region has been observed earlier and was ascribed 


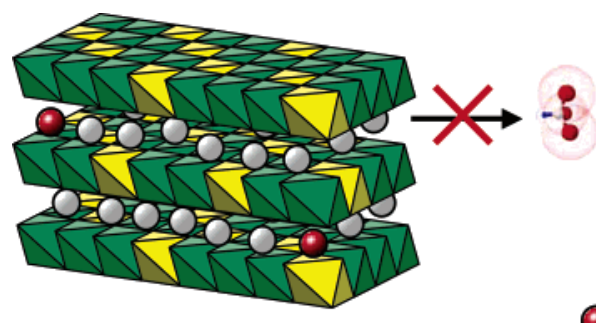

\section{Accessibility $<<$ Activity}

\section{- Active $\mathrm{OH}^{-}$ \\ Less active $\mathrm{OH}^{-}$}

Figure 11. Schematic representation of the difference in accessibility of the basic sites in HT-exc (left), with a preserved layer structure, and in HT-reh/HT-exr with a more distorted edge structure (right) when probing with $\mathrm{CDCl}_{3}$.

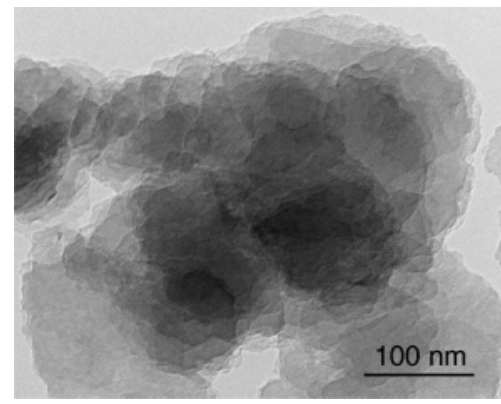

Figure 12. TEM micrograph of HT-exr, prepared by ion-exchange under reflux conditions.

to the interaction between $\mathrm{OH}$ groups with $\mathrm{Cl}$ atoms as well as with D (type A in Scheme 1). ${ }^{39,47,51}$ After switching off the $\mathrm{CDCl}_{3}$ feed, the bands discussed disappeared. The perturbation of the bands in the region $3300-3100 \mathrm{~cm}^{-1}$ remained unclear, but could originate from an interaction of the type $\mathrm{Cl}_{3} \mathrm{C}-$ $\mathrm{D} \cdot \mathrm{OH}^{-}$(type B in Scheme 1).

On the basis of the results from the adsorption of $\mathrm{CO}_{2}$ as measured with calorimetry and the adsorption of $\mathrm{CDCl}_{3}$ (IR), we can deduce that no significant differences in basic strength of the materials are apparent. On the basis of the calorimetric measurements, we would expect a much higher catalytic activity for HT-exc since there are more sites with a relatively high heat of adsorption toward $\mathrm{CO}_{2}$ in HT-exc than in HT-reh. The results from $\mathrm{CDCl}_{3}$ adsorption are revealing. No significant difference in the shift of $v_{\mathrm{CD}}$ is observed, but a large difference in intensity of the absorption band is apparent. The low amount of $\mathrm{CDCl}_{3}$ adsorbed on HT-exc is ascribed to steric hindrance preventing the formation of adsorption complexes between the Brønstedbase sites and $\mathrm{CDCl}_{3}$ due to the defect-free hexagonal structure of the platelets, as schematically represented in Figure 11. With HT-reh a more disordered structure was obtained, and due to this disordered structure the accessibility for $\mathrm{CDCl}_{3}$ of the Brønsted-base sites was enhanced. We propose that the enhanced accessibility of chloroform and, similarly, for acetone is a key characteristic of hydrotalcite catalysts active in condensation reactions.

Consequences of the New Model. The new structural model was tested by enhancing the accessibility of activated HT obtained via ion-exchange. To distort the edge structure of the platelets we used modified ion-exchange methods, which involved the ion-exchange of HT-oxa in aqueous $\mathrm{KOH}$ under reflux conditions (HT-exr). Figure 12 shows a representative TEM micrograph of HT-exr. It appeared that upon ion-exchange in boiling solution the hexagonal platelet structure of the assynthesized material has been severely altered. Although a platelet-like structure could still be distinguished, the edge structure of the platelets appeared to be frayed and the morphology of the platelets, in particular at the edges, seemed to be more distorted.
The results from $\mathrm{N}_{2}$ physisorption of HT-exr (Table 2) are in line with the observations with TEM; the increase in surface area and pore volume indicate roughening of the surface. The initial heat of adsorption of $\mathrm{CO}_{2}$ as measured by calorimetry of HT-exr appeared to be the same as the values for HT-exc and HT-reh (Table 3). In Figure 9 the DRIFT spectrum of $\mathrm{CDCl}_{3}$ adsorbed on HT-exr is displayed. Although the strength of the basic sites in HT-exr appeared to be the same as HT-exc, the adsorbed amount of $\mathrm{CDCl}_{3}$ on HT-exr was found to be much larger and points to an increase in accessibility of the Brønstedbase sites brought about by performing the ion-exchange under reflux conditions. As a consequence of the modifications of the edge structure, a large enhancement in catalytic activity in the condensation of acetone was observed compared to the activity of HT-exc (Figure 6, Table 3).

Finally, structure modifications induced by performing the ion-exchange under ultrasonic treatment were investigated. We found similar results when performing the ion-exchange under ultrasonic treatment to that performed under reflux conditions, i.e., a more distorted edge structure and enhanced catalytic performance. Cavitation damage ${ }^{58,59}$ most likely is the cause of the generation of edge defects. The conclusions based on these results may also explain the large enhancement in catalytic activity of hydrotalcites activated via rehydration in combination with ultrasonic treatment. ${ }^{5}$

Another approach to enhance the catalytic activity of activated hydrotalcites, of course, is to decrease the lateral size of the HT platelets in order to increase the number of active edge sites. In recent work, ${ }^{12,16}$ we showed that it is possible to prepare very small HT platelets $(\sim 20 \mathrm{~nm})$ supported on carbon nanofibers and that the resulting catalysts exhibited a very high catalytic activity in the condensation of citral with acetone and in the self-condensation of acetone.

\section{Conclusions}

Two different procedures have been applied to activate hydrotalcites for liquid-phase condensation reactions, i.e., heat treatment/rehydration and aqueous ion-exchange. With the latter the hexagonal platelet structure of the as-synthesized material could be preserved, whereas a more irregular structure was found for the rehydrated sample. From the microcalorimetric measurements of the adsorption of $\mathrm{CO}_{2}$ as well as from IR of the adsorption of $\mathrm{CDCl}_{3}$, no significant differences in strength of the basic sites were apparent. However, a high amount of $\mathrm{CDCl}_{3}$ was adsorbed on the rehydrated samples in contrast to the exchanged sample. The rehydrated catalyst exhibited an activity in the condensation of acetone 10-fold higher than that of the exchanged catalyst. An enhanced accessibility of the edge sites situated at the distorted edges of the platelets of rehydrated hydrotalcites is proposed. By performing the ion-exchange under reflux conditions or by ultrasonic treatment, the edge structure 
could be distorted too, hereby increasing the accessibility of the Brønsted-base sites and thus enhancing largely its catalytic activity. This study shows that not the strength but the accessibility of the basic sites largely determines the catalytic performance of activated hydrotalcites. Moreover, it is shown that with a probe molecule similar in size to the reactant molecule (acetone) we can assess relevant steric effects.

Acknowledgment. The authors are grateful to C. van der Spek, V. Koot, A. J. M. Mens, and F. Soulimani for their technical assistance. Professor J. W. Geus is acknowledged for the TEM analysis and useful discussions. The Netherlands Technology Foundation (CW/STW 790.35.733) is acknowledged for financial support.

\section{References and Notes}

(1) Motokura, K.; Fujita, N.; Mori, K.; Mizugaki, T.; Ebitani, K.; Kaneda, K. J. Am. Chem. Soc. 2005, 127, 9674-9675.

(2) Choudary, B.; Kantam, M. L.; Reddy, C. R. V.; Rao, K. K.; Figueras, F. J. Mol. Catal. A: Chem. 1999, 146, 279-284.

(3) Climent, M. J.; Corma, A.; Iborra, S.; Velty, A. J. Catal. 2004, $221,474-482$.

(4) Climent, M. J.; Corma, A.; Iborra, S.; Velty, A. Catal. Lett. 2002, 79, $157-163$.

(5) Abelló, S.; Medina, F.; Tichit, D.; Pérez-Ramírez, J.; Cesteros, Y.; Salagre, P.; Sueiras, J. E. Chem. Commun. 2005, 11, 1453-1455.

(6) Abelló, S.; Medina, F.; Tichit, D.; Pérez-Ramírez, J.; Groen, J. C.; Sueiras, J. E.; Salagre, P.; Cesteros, Y. Chem. Eur. J. 2005, 11, 728-739.

(7) Guida, A.; Hassane, L. M.; Tichit, D.; Figueras, F.; Geneste, P. Appl. Catal., A 1997, 164, 251-264.

(8) Rao, K. K.; Gravelle, M.; Sanchez-Valente, J.; Figueras, F. J. Catal. 1998, $173,115-121$.

(9) Roelofs, J. C. A. A.; Lensveld, D. J.; van Dillen, A. J.; de Jong, K. P. J. Catal. 2001, 203, 184-191.

(10) Roelofs, J. C. A. A.; van Dillen, A. J.; de Jong, K. P. Catal. Today 2000, 60, 297-303.

(11) Tichit, D.; Benanni, M. N.; Figueras, F.; Tessier, R.; Kervennal, J. Appl. Clay Sci. 1998, 13, 401-415.

(12) Winter, F.; van Dillen, A. J.; de Jong, K. P. Chem. Commun. 2005, 31, 3977-3979.

(13) Winter, F.; van Dillen, A. J.; de Jong, K. P. J. Mol. Catal. A: Chem. 2004, 219, 273-281.

(14) Sels, B. F.; de Vos, D. E.; Jacobs, P. A. Catal. Rev. -Sci. Eng. 2001, 43, 443-488.

(15) Cavani, F.; Trifiro, F.; Vaccari, A. Catal. Today 1991, 11, 173301.

(16) Winter, F.; Koot, V.; van Dillen, A. J.; Geus, J. W.; de Jong, K. P. J. Catal. 2005, 236, 91-100.

(17) Roelofs, J. C. A. A.; van Dillen, A. J.; de Jong, K. P. Catal. Lett. 2001, 74, 91-94.

(18) Prinetto, F.; Tichit, D.; Teissier, R.; Coq, B. Catal. Today 2000, $55,103-116$.

(19) Miyata, S. Clays Clay Miner. 1980, 28, 50-56.

(20) Titulaer, M. Ph.D. Thesis, Utrecht University, The Netherlands, 1993.

(21) Miyata, S. Clays Clay Miner. 1983, 31, 305-311.

(22) Carlino, S. Solid State Ionics 1997, 98, 73-84.

(23) Sanchez Valente, J.; Figueras, F.; Gravelle, M.; Kumbhar, P.; Lopez, J.; Besse, J.-P. J. Catal. 2000, 189, 370-381.
(24) Naumann d'Alnoncourt, R.; Kurtz, M.; Wilmer, H.; Löffler, E.;

Hagen, V.; Shen, J.; Muhler, M. J. Catal. 2003, 220, 249-253.

(25) Reichle, W. T. Solid State Ionics 1986, 22, 135-141.

(26) Reichle, W. T.; Kang, S. Y.; Everhardt, D. S. J. Catal. 1986, 101 , $352-359$.

(27) Bailly, M.-L.; Chizallet, C.; Costentin, G.; Krafft, J.-M.; Lauron-

Pernot, H.; Che, M. J. Catal. 2005, 235, 413.

(28) Roeffaers, M. B. J.; Sels, B. F.; Uji-i, H.; de Schryver, F. C.; Jacobs, P. A.; de Vos, D. E.; Hofkens, J. Nature 2006, 439, 572-575.

(29) Bouarab, R.; Cherifi, O.; Auroux, A. Thermochim. Acta 2005, 434 69.

(30) Casenave, S.; Martinez, H.; Guimon, C.; Auroux, A.; Hulea, V.; Cordoneanu, A.; Dumitriu, E. Thermochim. Acta 2001, 379, 85-93.

(31) Li, J.; Davis, R. J. Appl. Catal., A 2003, 239, 59.

(32) Prescott, H. A.; Li, Z.-J.; Kemnitz, E.; Trunschke, A.; Deutsch, J.; Lieske, H.; Auroux, A. J. Catal. 2005, 234, 119.

(33) Shen, J.; Kobe, J. M.; Chen, Y.; Dumesic, J. A. Langmuir 1994 $10,3902-3908$

(34) Shen, J.; Tu, M.; Hu, C. J. Solid State Chem. 1998, 137, 295301.

(35) Veldurthy, B.; Clacens, J.-M.; Figueras, F. J. Catal. 2005, 229, $237-242$.

(36) Bordawekar, S. V.; Davis, R. J. J. Catal. 2000, 189, 79.

(37) Stanimirova, T.; Piperov, N.; Petrova, N.; Kirov, G. Clay Miner. 2004, 39, 177-191.

(38) Prinetto, F.; Ghiotti, G.; Durand, R.; Tichit, D. J. Phys. Chem. B 2000, 104, 11117-11126.

(39) Davydov, A. A.; Shepot'ko, M. L.; Budneva, A. A. Kinet. Catal. 1994, 35, 299-306.

(40) Davydov, A. A. In Molecular spectroscopy of oxide catalyst surfaces; Sheppard, N. T., Ed.; Wiley: Chichester, 2003; pp 171-177.

(41) Di Cosimo, J. I.; Díez, V. K.; Xu, M.; Iglesia, E.; Apesteguía, C. R. J. Catal. 1998, 178, 499-510.

(42) Knözinger, H.; Huber, S. J. Chem. Soc., Faraday. Trans. 1998, 94, 2047-2059.

(43) Kustov, L. M. Top. Catal. 1997, 4, 131-144.

(44) Lavalley, J. C. Catal. Today 1996, 27, 377-401.

(45) Paukshtis, E. A.; Soltanov, P. I.; Yurchenko, E. N.; Jiratova, K. Collect. Czech. Chem. Commun. 1982, 47, 2044-2060.

(46) Paukshtis, E. A.; Kotsarenko, N. S.; Karakchiev, L. G. React. Kinet Catal. Lett. 1979, 12, 315-319.

(47) Delsarte, S.; Maugé, F.; Lavalley, J. C.; Grange, P. Catal. Lett. 2000, 68, 79-83.

(48) Delsarte, S.; Auroux, A.; Grange, P. Phys. Chem. Chem. Phys. 2000, $2,2821-2827$.

(49) Zaki, M. I.; Hussein, G. A. M.; Mansour, S. A. A.; Ismail, H. M.; Mekhemer, G. A. H. Colloids Surf., A 1997, 127, 47-56.

(50) Berteau, P.; Kellens, M.-A.; Delmon, B. J. Chem. Soc., Faraday Trans. 1991, 87, 1425-1431.

(51) López-Salinas, E.; Garcia-Sanchez, M.; Llanos-Serrano, M. E.; Navarrete-Bolanoz, J. J. Phys. Chem. B 1997, 101, 5112-5117.

(52) Lopez, T.; Gómez, R.; Llanos, M. E.; García-Figueroa, E.; Navarrete, J.; López-Salinas, E. Mater. Lett. 1999, 39, 51-57.

(53) Wiame, H. M.; Cellier, C. M.; Grange, P. J. Phys. Chem. B 2000 104, 591-596.

(54) Wiame, H.; Cellier, C.; Grange, P. J. Catal. 2000, 190, 406-418.

(55) Szöllösi, G.; Bartók, M. Catal. Lett. 1999, 59, 179-185.

(56) Szöllösi, G.; Bartók, M. J. Mol. Struct. 1999, 482-483, 13-17. 127.

(58) Lohse, D. Phys. Today 2003, 56, 36-41.

(59) Climent, M. J.; Corma, A.; Iborra, S.; Epping, K.; Velty, A. J. Catal. 2004, 225, 316-326. 